\title{
The first report of Lewis acid reagents in the intramolecular Rauhut-Currier reaction
}

\author{
Andrew T. Krasley and William P. Malachowski* \\ Chemistry Department, Bryn Mawr College, Bryn Mawr, PA 19010, USA \\ wmalacho@brynmawr.edu
}

\begin{abstract}
The first report of Lewis acid use in intramolecular Rauhut-Currier reactions is described. Titanium Lewis acids lead to rapid Rauhut-Currier reactions in the case of two classic substrates. More importantly, titanium and tin Lewis acids were the only successful reagent for a more complex substrate, thereby illustrating the potential for Lewis acid reagents to facilitate challenging intramolecular RauhutCurrier reactions that fail with traditional reagents.
\end{abstract}

Graphical abstract:

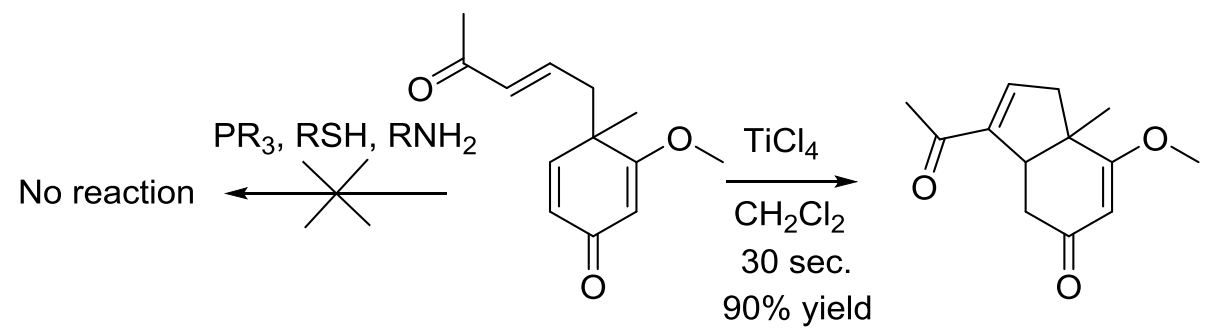

Keywords: Lewis acid, Rauhut-Currier, conjugate addition, bicarbocyclic synthesis

Lewis acids are an extremely effective reagent for a variety of chemical transformations and the wealth of review articles ${ }^{1}$ describing their many applications serves to illustrate their value. Lewis acids provide a selection of benefits, two of the most important being permitting catalytic processes and influencing stereoselectivity in a reaction by controlling transition state geometry. Included among the reactions that have been facilitated by Lewis acids is the Morita-Baylis-Hilman (MBH) reaction ${ }^{2}$. Surprisingly, the use of Lewis acids to facilitate the related vinylogous version of the MBH reaction, the Rauhut-Currier reaction ${ }^{3}$, has not, to the best of our knowledge, been reported. Two reports describe a similar process, but in both cases the final elimination step of the Rauhut-Currier was not achieved and the nucleophle was retained in the product. ${ }^{4}$ Furthermore, in 2008 Scheidt et al. reported ${ }^{5}$ the use of scandium triflate with silyloxyallenes to afford products that were equivalent to an intermolecular Rauhut-Currier reaction, albeit by a different reaction mechanism. Given the rich history of Lewis acid reagents facilitating catalytic and enantioselective processes in other reactions, the demonstration of Lewis acid reagent use in the Rauhut-Currier reaction might create an opportunity for similar valuable applications. Herein we report the first example of Lewis acid reagents use in intramolecular Rauhut-Currier reactions.

Studies commenced with a classic dienone intramolecular Rauhut-Currier substrate 1a, which was synthesized following literature procedures. ${ }^{6}$ Subjecting (E,E)-3,7-decadiene-2,9-dione 1a to traditional Rauhut-Currier reaction conditions, catalytic trimethylphosphine, provided the desired product in two hours similar to previous reports ${ }^{7}$ (Table 1, entry 1). Exposing 1a to stoichiometric titanium tetrachloride 
provided the same product in approximately 20 minutes (Table 1, entry 2). Sub-stoichiometric amounts of the titanium reagent were permitted (Table 1, entry 3 and 4), but the reaction slowed and then was not possible below 0.25 equivalents (Table 1 , entry 5 ). Since 0.25 equivalents of titanium tetrachloride equates to one equivalent of chloride relative to dienone substrate $1 \mathbf{a}$, we hypothesized that the chloride was being displaced upon Lewis acid binding to the dienone substrate and then performing a reversible conjugate addition (Scheme 1); much like the phosphine or amine catalysts typically used in Rauhut-Currier reactions.

Table 1. Titanium and tin reagents for dienones.<smiles>CC(=O)/C=C/CC/C=C/C(C)=O</smiles>

1a

2a

\begin{tabular}{|c|c|c|c|c|c|c|}
\hline entry & reagent & equiv. & additives $^{a}$ & $T\left[{ }^{\circ} \mathrm{C}\right]$ & $t[h]$ & $\%$ conversion \\
\hline 1 & $\mathrm{PMe}_{3}$ & 0.1 & - & r.t & 2 & 100 \\
\hline 2 & $\mathrm{TiCl}_{4}$ & 1.2 & - & r.t & 0.33 & 100 \\
\hline 3 & $\mathrm{TiCl}_{4}$ & 0.5 & - & r.t. & 0.67 & 92 \\
\hline 4 & $\mathrm{TiCl}_{4}$ & 0.25 & - & r.t. & 18 & 87 \\
\hline 5 & $\mathrm{TiCl}_{4}$ & 0.1 & - & r.t. & 24 & 0 \\
\hline 6 & $\mathrm{TiCl}_{4}$ & 0.1 & $\mathrm{LiCl}$ & r.t & 1 & 0 \\
\hline 7 & $\mathrm{TiCl}_{4}$ & 0.1 & LiCl/12-crown-4 & r.t & 19 & 0 \\
\hline 8 & $\mathrm{TiCl}_{4}$ & 0.26 & $(\mathrm{n}-\mathrm{Bu})_{4} \mathrm{NI}(0.26$ eq. $)$ & r.t & 22 & 0 \\
\hline 9 & $\mathrm{TiCl}_{4}$ & 1.2 & $\mathrm{t}-\mathrm{BuOH}$ & r.t.--> $\Delta$ & 72 & 0 \\
\hline 10 & $\mathrm{TiCl}_{4}$ & 1.2 & $\mathrm{PMe}_{3}$ & r.t.--> $\Delta$ & 48 & 0 \\
\hline 11 & $\mathrm{TiCl}_{4}$ & 1.2 & DABCO & r.t. & 20 & 0 \\
\hline 12 & $\mathrm{TiCl}_{4}$ & 1.2 & $\mathrm{PhSH}$ & r.t.--> $\Delta$ & 48 & 0 \\
\hline 13 & $\mathrm{TiCl}_{4}$ & 1.2 & $\mathrm{PhSNa}$ & r.t.--> $\Delta$ & 48 & 0 \\
\hline 14 & $\mathrm{TiBr}_{4}$ & 0.5 & - & r.t. & 43 & 100 \\
\hline 15 & $\mathrm{Ti}(\mathrm{OiPr})_{4}$ & 2.3 & - & $\Delta$ & 19 & 0 \\
\hline 16 & $\mathrm{Ti}(\mathrm{OiPr})_{4}$ & 2.3 & $\mathrm{LiCl}$ (3.5 eq.) & $\Delta$ & 19 & 0 \\
\hline 17 & $\mathrm{Ti}(\mathrm{OiPr})_{3} \mathrm{Cl}$ & 1.0 & - & $\Delta$ & 13 & 0 \\
\hline 18 & $\mathrm{SnCl}_{4}$ & 1.2 & - & r.t. & 88 & 0 \\
\hline 19 & $\mathrm{SnBr}_{4}$ & 0.5 & - & r.t. & 91 & 0 \\
\hline 20 & $\mathrm{AlCl}_{3}$ & 1.2 & - & r.t. & 19 & 0 \\
\hline 21 & $\mathrm{BCl}_{3}$ & 1.2 & - & r.t. & 1.5 & 0 \\
\hline 22 & BINOL- $\left(\mathrm{PO}_{4} \mathrm{H}\right)$ & 1.2 & - & r.t.--> $\Delta$ & 48 & 0 \\
\hline
\end{tabular}

${ }^{a} 1.0$ equiv. unless otherwise stated. ${ }^{b}$ yield based on GCMS. 
Scheme 1. Proposed reaction mechanism.
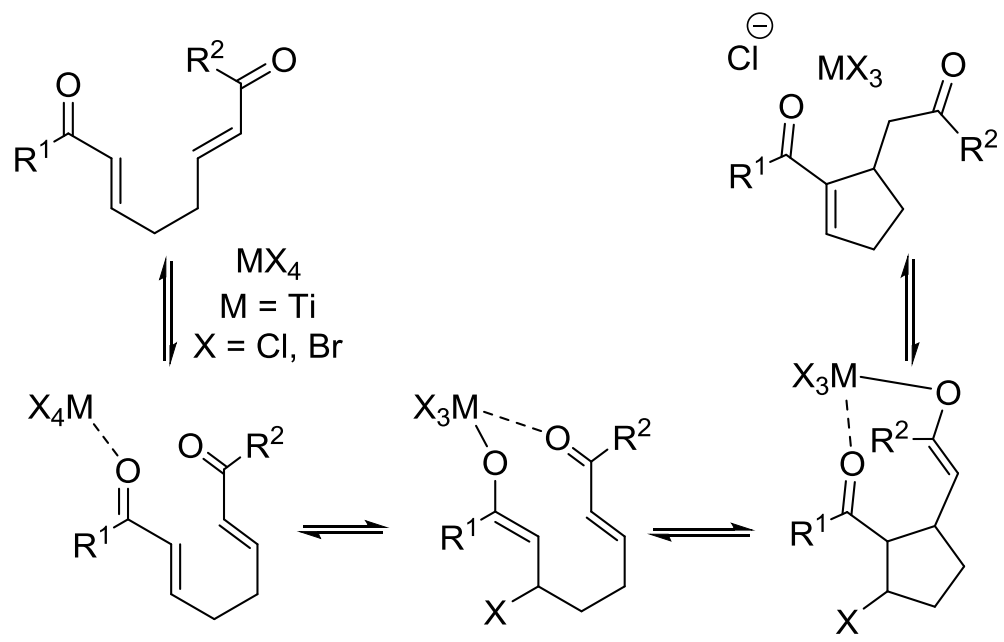

Attempts to combine the Lewis acid with various nucleophiles to make the process catalytic were unsuccessful. Addition of a full equivalent of $\mathrm{LiCl}$ (Table 1, entry 6 and 7) or an iodide nucleophile (entry 8) failed to afford any product. In fact, the added chloride ion was actually found to suppress the reaction (vide infra). In situ generation of titanium tert-butoxide and liberation of chloride ion similarly failed to provide any product (entry 9). The combination of traditional Rauhut-Currier nucleophiles and titanium tetrachloride also did not afford any product by GC analysis (entries 10-13). Titanium tetrabromide worked (entry 14), albeit more slowly, which might be expected in an aprotic solvent like $\mathrm{CH}_{2} \mathrm{Cl}_{2}$ where the bromide ion would be less nucleophilic than the chloride ion of titanium tetrachloride. Less electrophilic titanium tetraisopropoxide did not work with or without additional LiCl (entry 15 and 16). Incorporation of the nucleophilic chloride into the titanium complex with $\mathrm{Ti}(\mathrm{OiPr})_{3} \mathrm{Cl}$ also failed to afford product (entry 17). The strength of the Lewis acid was critical based on the failure of tin tetrahalides (entry 18 and 19). However, the stronger Lewis acids, aluminum and boron (entry 20 and 21), afforded a complex mixture of products, despite evidence for formation of the halide conjugate addition intermediate during GC analysis of the reaction. The failure of aluminum and boron also suggests that the valence of the Lewis acid may also be critical to the success of the intramolecular Rauhut-Currier reaction. Finally, a chiral phosphoric acid, which has been used to promote other conjugate addition reactions, ${ }^{8}$ also failed to afford any product (entry 22 ). In summary, the reaction was quite efficient with at least 0.25 equivalent of titanium tetrahalide. The electrophilicity and valence of the Lewis acid is critical and the addition of other nucleophiles did not stimulate the reaction.

Exploring the substrate scope of the process with two other classic intramolecular Rauhut-Currier substrates, $\mathbf{3}^{5 \mathrm{~b}}$ and $\mathbf{4}^{\mathbf{9}}$, demonstrated only modest range (Table 2). Cyclopentene formation was the most facile (Table 2, entry 1), but was limited to the more electrophilic diketone substrates; the introduction of even one ester prevented any reaction (Table 2, entry 2). With cyclohexenes, only the non-enolizable diphenyl derivative was successful (Table 2, entry 4); presumably the ability of the 
dimethyl example to undergo enolization hinders the Rauhut-Currier process. Attempted cycloheptene formation also failed with both enolizable (dimethyl) and non-enolizable (diphenyl) substrates (Table 2, entries 5 and 6). Finally, an intermolecular Rauhut-Currier reaction with methyl vinyl ketone and tin tetrachloride lead only to products of polymerization (not shown); not surprising given the prevalence of cationic polymerization practices ${ }^{10}$.

Table 2. Dienones subjected to Lewis acid Rauhut-Currier.<smiles>[R]C(=O)/C=C\CCCCCC([R])=O</smiles>

\begin{tabular}{|c|c|c|c|c|c|c|c|}
\hline entry & compd & $n$ & $R^{1}$ & $R^{2}$ & temp. & $t[h]$ & $\%$ isolated yd. \\
\hline 1 & $\mathbf{1 a}$ & 1 & $\mathrm{Me}$ & $\mathrm{Me}$ & r.t. & 0.33 & $80 \%$ \\
\hline 2 & $\mathbf{1 b}$ & 1 & $\mathrm{Me}$ & $\mathrm{OMe}$ & $\Delta$ & 24 & $0 \%$ \\
\hline 3 & $\mathbf{3 a}$ & 2 & $\mathrm{Me}$ & $\mathrm{Me}$ & $\Delta$ & 24 & $0 \%$ \\
\hline $4^{\mathrm{a}}$ & $\mathbf{3 b}$ & 2 & $\mathrm{Ph}$ & $\mathrm{Ph}$ & r.t & 3.33 & $78 \%$ \\
\hline 5 & $\mathbf{4 a}$ & 3 & $\mathrm{Me}$ & $\mathrm{Me}$ & $\Delta$ & 24 & $0 \%$ \\
\hline 6 & $\mathbf{4 b}$ & 3 & $\mathrm{Ph}$ & $\mathrm{Ph}$ & $\Delta$ & 24 & $0 \%$ \\
\hline
\end{tabular}

${ }^{a}$ t-BuOK added after 20 minutes and reacted for 3 hours to eliminate $\mathrm{Cl}$.

In pursuit of complex natural product-like intermediates for the generation of potentially bioactive compounds, we also explored the use of Lewis acids for Rauhut-Currier formation on a more complex substrate, $\mathbf{5}$ (see Supporting Information for synthesis of 5). As shown in Table 3, a wide array of classic Rauhut-Currier reaction conditions failed to afford any product (entries 1-10). Presumably the reaction was hindered by sterics and the presence of a less electrophilic vinylogous ester for the second conjugated alkene.

Table 3. Intramolecular Rauhut-Currier reaction with complex substrate.

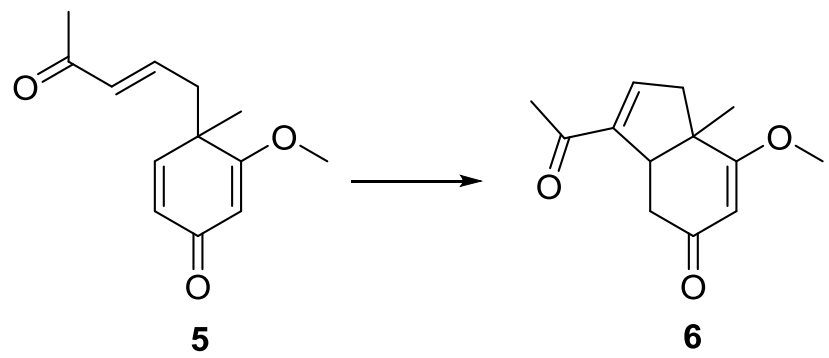

\begin{tabular}{|c|c|c|c|c|c|c|}
\hline entry & reagent & additives & solvent & $T\left[{ }^{\circ} \mathrm{C}\right]$ & $t[\mathrm{~h}]$ & $\begin{array}{c}\% \text { isolated } \\
y d .\end{array}$ \\
\hline
\end{tabular}




\begin{tabular}{|c|c|c|c|c|c|c|}
\hline 1 & $\mathrm{PMe}_{3}(0.2 \mathrm{eq})$ & - & $\mathrm{CH}_{2} \mathrm{Cl}_{2}$ & $0-$ r.t. & 24 & $0 \%$ \\
\hline 2 & $\mathrm{PMe}_{3}(1.2 \mathrm{eq})$ & $\mathrm{t}-\mathrm{BuOH}$ & $\mathrm{CH}_{2} \mathrm{Cl}_{2}$ & $0-$ r.t. & 24 & $0 \%$ \\
\hline 3 & $\mathrm{PhSH}(1.0 \mathrm{eq})$ & - & $\mathrm{CH}_{2} \mathrm{Cl}_{2}$ & $0-$ r.t. & 24 & $0 \%$ \\
\hline 4 & PhSH (1.0 eq) & $\mathrm{NaH}(1.5 \mathrm{eq})$ & $\mathrm{CH}_{2} \mathrm{Cl}_{2}$ & $0-$ r.t. & 24 & $0 \%{ }^{a}$ \\
\hline 5 & $\mathrm{PhSNa}(0.2 \mathrm{eq})$ & $\mathrm{Sc}(\mathrm{OTf})_{3}$ & THF & $\Delta$ & 24 & $0 \%$ \\
\hline 6 & $\mathrm{BnNH}_{2}(1.5 \mathrm{eq})$ & $\mathrm{Et}_{3} \mathrm{~N}$ (excess) & Toluene & $\Delta$ & 24 & $0 \%$ \\
\hline 7 & $\mathrm{BnNH}_{2}(20$ eq) & $\mathrm{BF}_{3} \cdot \mathrm{Et}_{2} \mathrm{O}$ & THF & r.t. & 24 & $0 \%$ \\
\hline 8 & $\mathrm{MeNH}_{2}(20 \mathrm{eq})$ & $\mathrm{Et}_{3} \mathrm{~N}(30 \mathrm{eq})$ & THF & r.t. & 24 & $0 \%$ \\
\hline 9 & $\mathrm{MeNH}_{2}(20 \mathrm{eq})$ & $\mathrm{Sc}(\mathrm{OTf})_{3}$ & THF & r.t. & 24 & $0 \%$ \\
\hline 10 & BocCysOMe (1.0 eq) & t-BuOK (6.0 eq) & $\mathrm{ACN} / \mathrm{H}_{2} \mathrm{O}$ & r.t. & 24 & $0 \%$ \\
\hline 11 & $\mathrm{TiCl}_{4}(1.2 \mathrm{eq})$ & - & $\mathrm{CH}_{2} \mathrm{Cl}_{2}$ & r.t. & $\begin{array}{c}30 \\
\text { sec }\end{array}$ & $90 \%$ \\
\hline 12 & $\mathrm{SnCl}_{4}(1.2 \mathrm{eq})$ & - & $\mathrm{CH}_{2} \mathrm{Cl}_{2}$ & r.t. & 0.5 & $85 \%$ \\
\hline 13 & $\mathrm{SnCl}_{4}(1.2 \mathrm{eq})$ & $\mathrm{LiCl}(2.4 \mathrm{eq})$ & $\mathrm{CH}_{2} \mathrm{Cl}_{2}$ & r.t. & 1 & $53 \%$ \\
\hline 14 & $\mathrm{AlCl}_{3}(1.2 \mathrm{eq})$ & - & $\mathrm{CH}_{2} \mathrm{Cl}_{2}$ & r.t. & 1 & $0 \%$ \\
\hline 15 & $\mathrm{BCl}_{3}(1.2 \mathrm{eq})$ & - & $\mathrm{CH}_{2} \mathrm{Cl}_{2}$ & r.t. & 10 & $0 \%$ \\
\hline 16 & $\mathrm{ZnCl}_{2}(1.2 \mathrm{eq})$ & - & $\mathrm{CH}_{2} \mathrm{Cl}_{2}$ & r.t. & 24 & $30 \% b$ \\
\hline 17 & $\mathrm{ZnI}_{2}(1.2 \mathrm{eq})$ & - & $\mathrm{CH}_{2} \mathrm{Cl}_{2}$ & r.t. & 24 & $0 \%$ \\
\hline 18 & $\mathrm{CuCl}_{2}(1.2 \mathrm{eq})$ & - & $\mathrm{CH}_{2} \mathrm{Cl}_{2}$ & r.t. & 24 & $0 \%$ \\
\hline
\end{tabular}

${ }^{a} 1,4$ addition product to acyclic enone observed. ${ }^{b}$ yield based on GCMS

Nevertheless, subjecting the same complex substrate to Lewis acid conditions afforded the product in exceptionally rapid fashion and high yield. Consistent with the previous studies of the classic RauhutCurrier substrate, 1a, the highest efficiency was seen with the most electrophilic tetravalent Lewis acid, $\mathrm{TiCl}_{4}$ (Table 3, entry 11). Surprisingly, and in contrast to studies with 1a, tin tetrachloride also worked quite well (Table 3, entry 12). Interestingly, the addition of $\mathrm{LiCl}$ with $\mathrm{SnCl}_{4}$ actually suppressed the Rauhut-Currier reaction (Table 3, entry 13). Since the presumed mechanism involves halide conjugate addition to one enone, extra chloride ion might be expected to facilitate the process. Instead, it appears that the extra halide actually suppresses Lewis acid binding to the enone oxygen atom. This must be a critical first step that is adversely impacted by the presence of excess halide. As before, the trivalent 
aluminum and boron reagents provided complex mixtures (entries 14 and 15), while the less electrophilic zinc and copper dihalides afforded little or no product (Table 3, entries 16-18).

In conclusion, the first study of Lewis acid reagent use in the intramolecular Rauhut-Currier reaction is reported. Although not broadly applicable, the reaction is exceptionally efficient with particular substrates and is the only successful choice in the more complex example that was tested. Given the range of additional benefits of Lewis acids illustrated in the variety of reactions chemists have conducted with these reagents, the demonstration of Lewis acid applicability to intramolecular Rauhut-Currier reactions should be a benefit. In addition, this study illustrates that substrates that are resistant to traditional Rauhut-Currier reagents might be feasible with Lewis acid reagents.

\section{Acknowledgements}

A generous award (CHE-0958996) from the National Science Foundation enabling acquisition of the 400 $\mathrm{MHz}$ NMR spectrometer used in these studies is gratefully acknowledged. The authors would also like to thank Bryn Mawr College for financial support of this work. The University of Delaware Mass Spectrometry Facility is acknowledged for acquiring all HRMS data.

\section{Supplementary data}

Experimental details including full characterization and spectra of all new compounds for this article are provided.

\section{References}

${ }^{1}$ For examples of reactions utilizing Lewis acids, see: a) Yamamoto, Y. J. Org. Chem. 2007, 72, 7817-7831. b) Christoffers, J.; Koripelly, G.; Rosiak, A.; Roessle, M. Synthesis 2007, 1279-1300. c) Denmark, S. E. and Fu, J. Chem. Rev., 2003, 103, 2763-2794. d) Corma, A. and García, H. Chem. Rev., 2002, 102, 3837-3892. e) E. J. Corey, E. J. Angew. Chem. Int.Ed. 2002, 41, 1650-1667. f) Johnson, J. S. and Evans, D. A. Acc. Chem. Res., 2000, 33, 325-335. g) Mahrwald, R. Chem. Rev., 1999, 99, 1095-1120.

${ }^{2}$ Morita-Baylis-Hillman reaction reviews: a) Zhao, M-X.; Wei, Y.; Shi, M. Catalytic Systems for the MoritaBaylis-Hillman Reaction. In The Chemistry of the Morita-Baylis-Hillman Reaction; Spivy, J.J. Ed.; RCS Publishing: Cambridge, U.K., 2011; pp 146-155. b) Masson, G.; Housseman, C.; and Zhu, J. Angew. Chem. Int. Ed., 2007, 46, 4614-4628. c) Ma, G.-N.; Jiang, J.-J.; Shi, M.; Wie, Y. Chem. Commun. 2009, 5496-5514. d) Declerck, V.; Martinez, J.; Lamaty, F. Chem. Rev. 2009, 109, 1-48. e) Carrasco-Sanchez, V.; Simirgiotis, M. J.; Santos, L. S. Molecules 2009, 14, 3989-4021. f) Basavaiah, D.; Reddy, B. S.; Badsara, S. S. Chem. Rev. 2010, 110, 5447-5674. g) Mansilla, J.; Saá, J. M. Molecules 2010, 15, 709-734. h) Wei, Y.; Shi, M. Acc. Chem. Res. 2010, 43, 1005-1018. i) Wang, S.-X.; Han, X.; Zhong, F.; Wang, Y.; Lu, Y. Synlett 2011, 27662778.

${ }^{3}$ a) Rauhut, M. M.; Currier, H. (American Cyanamid Co.), U.S. Patent 3,074,999, 1963; Chem. Abstr. 1963, 58, 11224a. b) Methot, J. L.; Roush, W. R. Adv. Synth. Catal. 2004, 346, 1035-1050. c) Aroyan, C. E.; Dermenci, A.; Miller, S. J. Tetrahedron 2009, 65, 4069-4084. d) Xie, P.; Huang, Y. Eur. J. Org. Chem. 2013, 6213-6226.

${ }^{4}$ a) Yagi, K.; Turitani, T.; Hiroshi Shinokubo, H.; Oshima, K. Organic Letters 2002, 4, 3111-3114. b)

Thirupathaiah, B.; Seo, S-Y. Chem. Commun. 2015, 51, 4216-4219.

${ }^{5}$ Reynolds, T. E.; Binkley, M. S.; Scheidt, K. A. Org. Lett. 2008, 10, 2449-2452.

${ }^{6}$ a) Fakstorp, J.; Raleigh, D.; Schniepp, L. E. J. Am. Chem. Soc. 1950, 72, 869-874; with modification from Grimsrud, E. P.; Taylor, J. W. J. Am. Chem. Soc. 1970, 92, 741-743. b) Black, G. P.; Murphy, P. J.; Walshe, N. D. A. Tetrahedron, 1998, 54, 9481-9488. 
${ }^{7}$ Fraink, S. A.; Mergott, D. J.; Roush, W. R. J. Am. Chem. Soc. 2002, 124, 2404-2405.

${ }^{8}$ Gu, Q.; Rong, Z-Q.; Zheng, C.; You, S-L. J. Am. Chem. Soc. 2010, 132, 4056-4057.

${ }^{9}$ a) VanRheenen, V.; Cha, D. Y.; Hartley, W. M. Org. Syn. Coll. Vol. 6, 1988, 348. b) López, S.; FernándezTrillo, F.; Midón, P.; Castedo, L.; Saá, C. J. Org. Chem., 2005, 70, 6346-6352.

${ }^{10}$ Aoshima, S.; Yoshida, T.; Kanazawa, A.; Kanaoka, S. J. Polymer Sci. Part A 2007, 45, 1801-1813. 